\title{
Evaluation of Carbon Ion Radiation-Induced Trismus in Head and Neck Tumors Using Dose-Volume Histograms
}

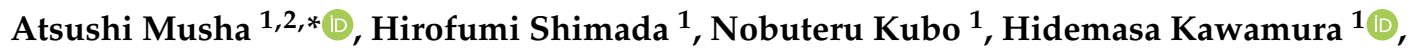 \\ Naoko Okano $^{1}$, Yuhei Miyasaka ${ }^{1} \mathbb{D}$, Hiro Sato ${ }^{1}$, Katsuyuki Shirai ${ }^{3}{ }^{\mathbb{D}}$, Jun-ichi Saitoh ${ }^{4}$, \\ Satoshi Yokoo ${ }^{2}$, Kazuaki Chikamatsu ${ }^{5}$ and Tatsuya Ohno ${ }^{1}$ (D) \\ 1 Gunma University Heavy Ion Medical Center, Maebashi, Gunma 371-8511, Japan; \\ shimada@gunma-u.ac.jp (H.S.); kubo@gunma-u.ac.jp (N.K.); kawa@gunma-u.ac.jp (H.K.); \\ okano.n@gunma-u.ac.jp (N.O.); y.miyasaka@gunma-u.ac.jp (Y.M.); hiro.sato@gunma-u.ac.jp (H.S.); \\ tohno@gunma-u.ac.jp (T.O.) \\ 2 Department of Oral and Maxillofacial Surgery/Plastic Surgery, Gunma University Graduate School of \\ Medicine, Maebashi, Gunma 371-8511, Japan; syokoo@gunma-u.ac.jp \\ 3 Department of Radiology, Jichi Medical University Hospital, Shimotsuke, Tochigi 329-0498, Japan; \\ kshirai@jichi.ac.jp \\ 4 Department of Radiation Oncology, Faculty of Medicine, University of Toyama, Toyama 930-0194, Japan; \\ junsaito@med.u-toyama.ac.jp \\ 5 Department of Otolaryngology-Head and Neck Surgery, Gunma University Graduate School of Medicine, \\ Maebashi, Gunma 371-8511, Japan; tikamatu@gunma-u.ac.jp \\ * Correspondence: musha@gunma-u.ac.jp; Tel.: +81-(27)-220-8378
}

Received: 23 September 2020; Accepted: 23 October 2020; Published: 25 October 2020

Simple Summary: Patients who receive carbon ion radiotherapy (C-ion RT) for tumors near the temporomandibular joint are likely to experience trismus, a condition characterized by reduced jaw opening. However, the relationship between the dose of carbon ion and the onset of trismus remains unclear. Therefore, we conducted a subgroup analysis of a prospective observational study to understand the relationship between the dose of carbon ion and the occurrence of trismus. Of 35 patients included in the study, six developed grade 2 trismus, and the median onset time was 12 months. The affected muscles included masticatory muscles and the coronoid process. Our findings suggest better treatment planning, such as dose optimization, to minimize the occurrence of muscle-related adverse effects associated with C-ion RT.

\begin{abstract}
Carbon ion radiotherapy (C-ion RT) provides a highly localized deposition of energy that can increase radiation doses to tumors while minimizing irradiation of adjacent normal tissues. For tumors located near the temporomandibular joint, C-ion RT-induced trismus may occur. However, the relationship between the carbon ion dose and the onset of trismus is unclear. In this prospective observational study, we assessed the trismus/carbon ion dose relationship using dose-volume histograms in 35 patients who received C-ion RT in their head and neck regions between 2010 and 2014. Trismus was evaluated in patients according to the Common Terminology Criteria for Adverse Events, version 4.0. All patients were treated with 57.6 or 64.0 Gy (relative biological effectiveness (RBE)) in 16 fractions, and the median follow-up time was 57 months. Grade 2 trismus was observed in six patients. The median onset time was 12 months. At maximum radiation doses, all masticatory muscles and coronoid processes, particularly the masseter muscle, were significantly different $(p=0.003)$. The contouring of the masseter muscle and coronoid process requires different treatment planning. The maximum radiation doses of the coronoid process can be proposed as a guideline for treatment planning, considering the ease of contouring in C-ion RT.
\end{abstract}


Keywords: carbon ion radiotherapy; head and neck tumor; carbon ion radiotherapy-induced trismus

\section{Introduction}

Head and neck tumor patients undergoing radiotherapy suffer from acute adverse events (mucositis and dermatitis), and late adverse events (dysgeusia, osteoradionecrosis, and trismus). Usually it is challenging to improve late adverse events that reduce the patient's quality of life (QOL). Radiation-induced trismus impacts the patient's QOL, making it difficult for them to open their mouths, to eat, to talk, and to maintain oral hygiene [1,2]. The prevalence of $X$-ray-induced trismus for head and neck tumors is $1.4-41 \%$ [3-11]. Previous studies showed trismus onset by $\mathrm{X}$-ray correlated significantly with the radiation dose received in the masseter muscles $[1,2,6,10,12]$, pterygoid muscles $[1,13,14]$, and in the temporomandibular joint [2,15], focusing efforts on reducing the radiation dose received by the above structures to mitigate the X-ray-induced onset of trismus. However, this is difficult when the tumor has invaded near the temporomandibular joint structures, increasing the concentration area of radiation-induced adverse events, since radiotherapy has become highly precise. In particular, a highly localized deposition by carbon ion radiotherapy (C-ion RT) energy can increase radiation doses to tumors while minimizing the irradiation area of adjacent, normal tissues. Previous studies have reported the incidence of trismus onset by C-ion RT. The prevalence of trismus by C-ion RT for head and neck tumors is 2-9\% [16-20]. Therefore, the relationship between C-ion RT and trismus is unclear.

This study aimed to identify the correlation between the maximum dose and the dose-volume histogram, and C-ion RT-induced trismus.

\section{Results}

\subsection{Incidence of C-Ion RT-Induced Trismus}

The median follow-up time was 57 months. C-ion RT-induced trismus was evaluated using the Common Terminology Criteria for Adverse Events (CTCAE), version 4.0. [21], and grade 2 or higher was considered as trismus. Grade 2 trismus was observed in six patients $(19.4 \%)$. There were no cases of grade 1 or 3 trismus. The median onset time was 12 months (range, 10-22 months). The trismus resolved entirely after 24 months of C-ion RT (Figure 1). Trismus onset showed no significant difference between the age, sex, primary site, histological type, T stage, and gross tumor volume (Table S1). 


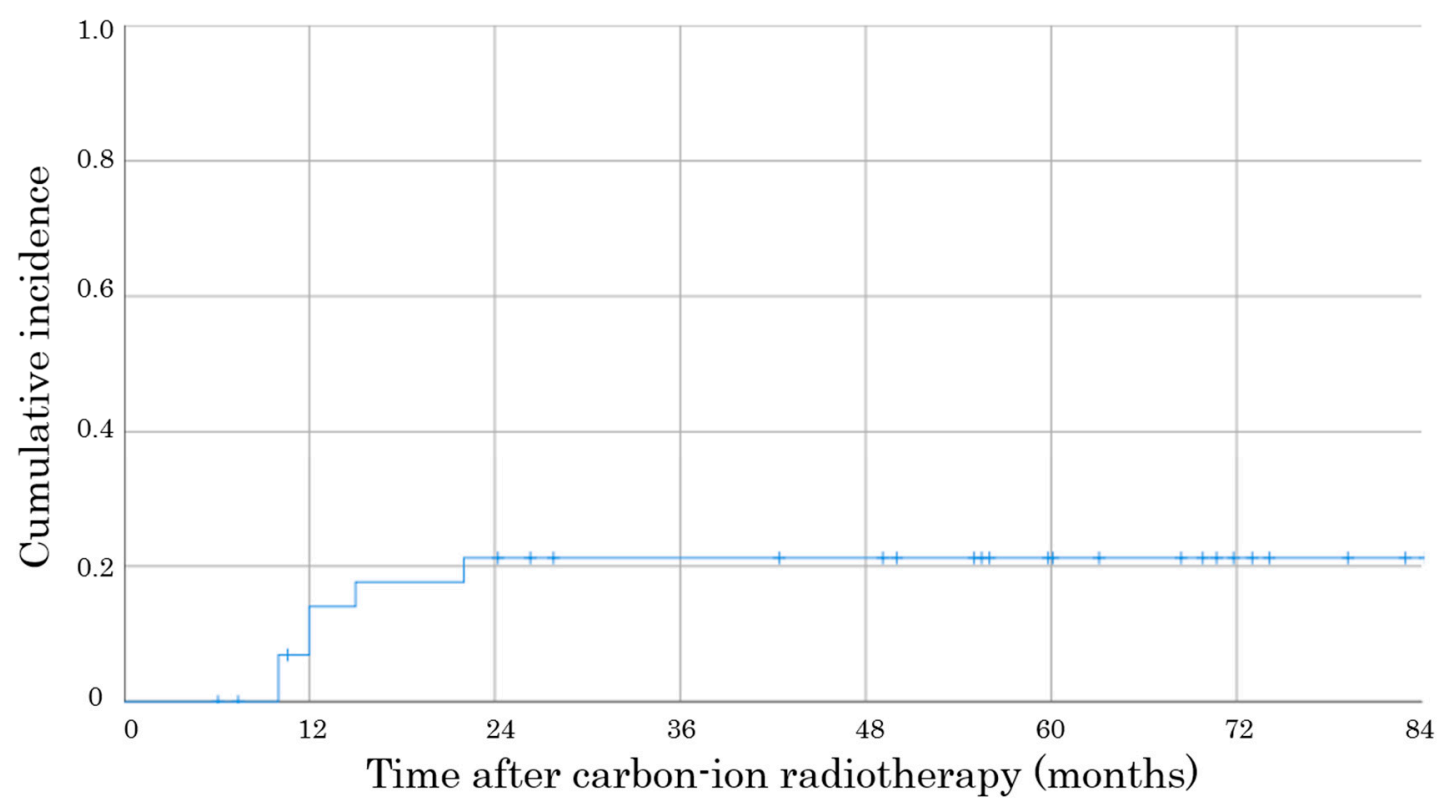

Number at risk (grade 2)

$\begin{array}{llllllll}31 & 26 & 22 & 21 & 18 & 12 & 6 & 1\end{array}$

Figure 1. Cumulative incidence of grade 2 carbon ion radiotherapy-induced trismus after carbon ion radiotherapy in patients with this study $(n=31)$.

2.2. Representative Images of a Tumor and Temporomandibular Joint-Related Muscles and Bones

Figure 2 shows a representative case of computed tomography images of the tumor and temporomandibular joint-related muscles and bones and a 3-dimensional image of the mandible. This patient had adenoid cystic carcinoma of the right maxillary sinus. The tumor and temporomandibular joint-related organs are close and irradiated with a high dose of radiation (Figure 2a). The masseter muscle, mandible head, and coronoid process were displayed on the 3 -dimensional image of the mandible (Figure 2b). The high-dose region can be seen in front of the masseter muscle and the coronoid process (Figure 2b). In this patient, trismus was onset at 22 months after C-ion RT. 

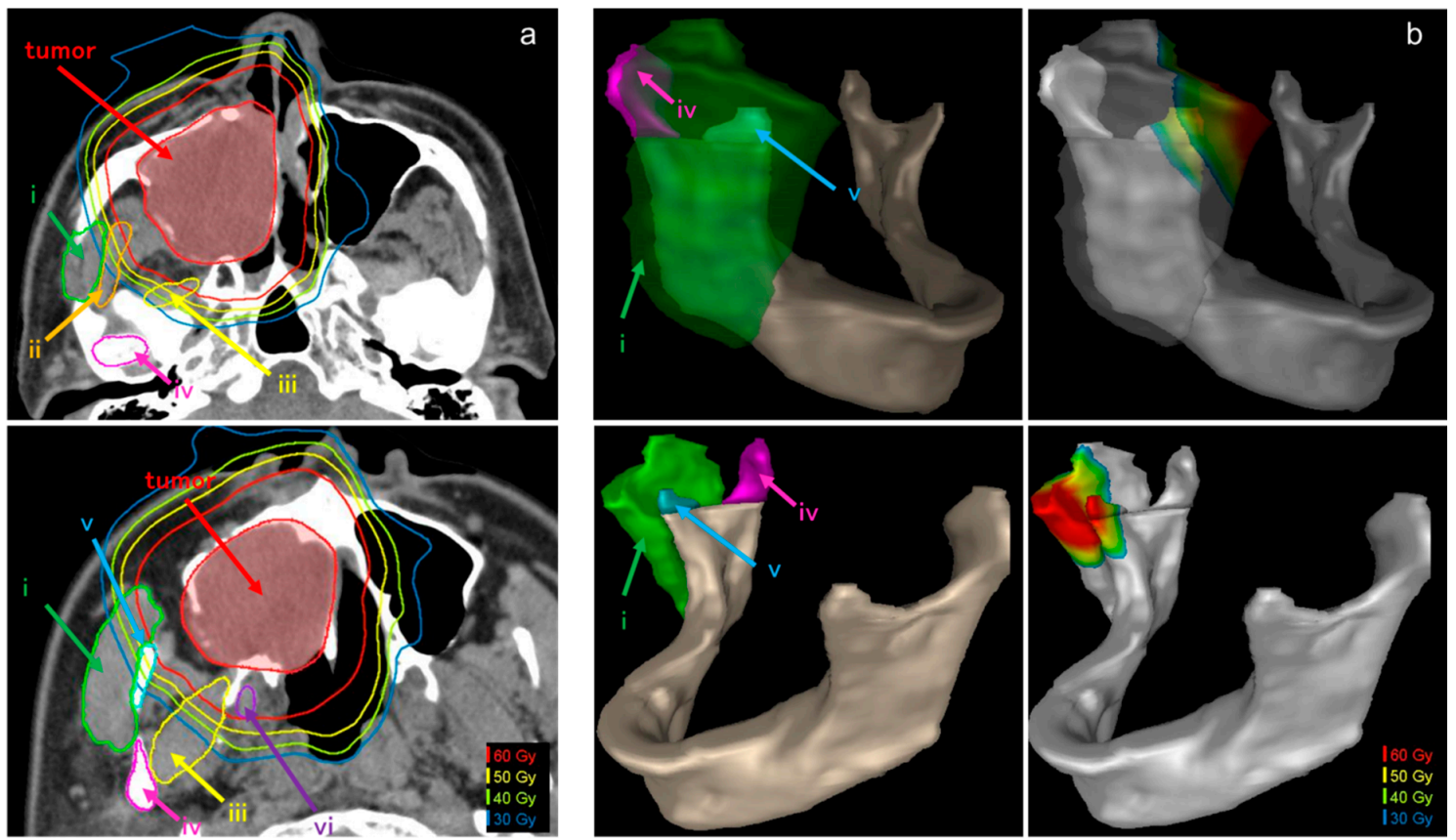

Figure 2. Representative case of computed tomography images of a tumor and temporomandibular joint-related muscles and bones and a 3-dimensional image of the mandible. (a) Computed tomography images of a tumor and temporomandibular joint-related muscles and bones. This patient with adenoid cystic carcinoma of the right maxillary sinus (T3NOM0). (b) The 3-dimensional image of the mandible with masseter muscle, mandible head, and coronoid process. The left figure shows the anatomical position. The figure on the right shows the dose distribution. (i) Masseter muscle, (ii) temporal muscle, (iii) lateral pterygoid muscle, (iv) mandible head, (v) coronoid process, and (vi) medial pterygoid muscle and tumor.

\subsection{Dose-Volume Histograms and C-Ion RT-Induced Trismus}

Figure 3 compares the dose-volume histogram (DVH) of the temporomandibular joint-related muscles and bones of patients with and without trismus. In the temporomandibular joint-related muscles, medial and lateral pterygoid muscle shared most of the high-dose area with or without trismus (Figure 3c,d). In contrast, the masseter muscle shared the least high-dose area with or without trismus (Figure 3a). The temporomandibular joint-related bones had different tendencies for DVH values with or without trismus (Figure $3 \mathrm{e}, \mathrm{f})$. In cases of trismus, the coronoid process tended to have a higher dose than the mandible head (Figure 3e,f). 

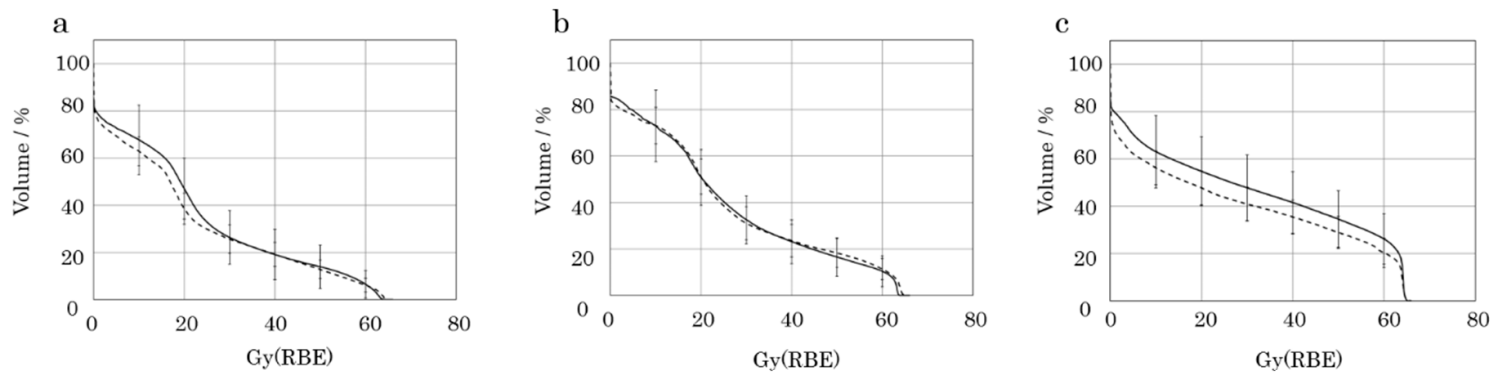

d
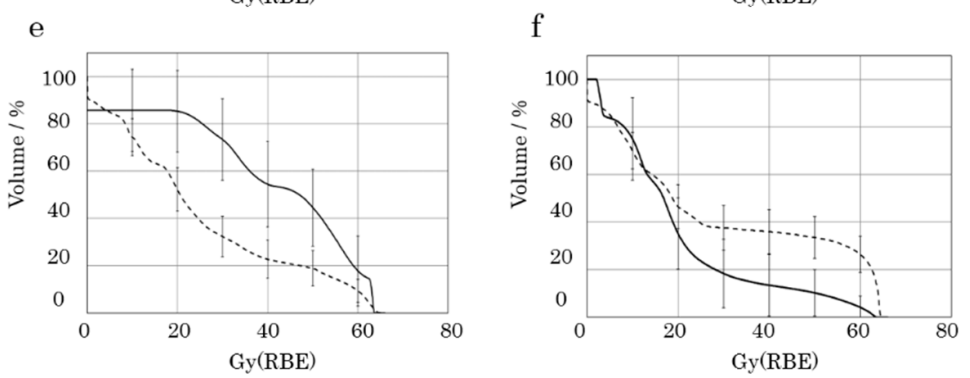

Figure 3. Comparison of dose-volume histograms and carbon ion radiotherapy-induced trismus. The vertical axis is the relative volume of the structure that received a higher dose than the absolute dose specified on the horizontal axis. (a) Masseter muscle, (b) temporal muscle, (c) medial pterygoid muscle, (d) lateral pterygoid muscle, (e) coronoid process, (f) mandible head. Continuous lines are with trismus, and dotted lines are without trismus.

\subsection{Maximum Dose in the Temporomandibular Joint-Related Structures and C-Ion RT-Induced Trismus}

The maximum radiation dose leading to no trismus or its onset was significantly different among various types of masticatory muscles (Table 1). In particular, the masseter muscle showed the most significant difference among its different muscles (Figure $4 \mathrm{a}$, Table 1, $p=0.003$ ). The maximum dose received by the masseter muscle that resulted in no trismus was $47.9 \pm 19.0 \mathrm{~Gy}(\mathrm{RBE})$, whereas the maximum dose that caused trismus was $61.2 \pm 5.9 \mathrm{~Gy}(\mathrm{RBE})$, which was significantly different. From the receiver operating characteristic (ROC) curve, the cut-off value was found to be $44.0 \mathrm{~Gy}(\mathrm{RBE}) \mathrm{for}$ trismus (sensitivity: 1.0, specificity: 0.44, AUC: 0.653, Table 1). In contrast, the difference between the maximum doses received by the bone structure of the temporomandibular that led to no trismus, $33.0 \pm 20.8 \mathrm{~Gy}(\mathrm{RBE})$, or trismus, $54.8 \pm 11.5 \mathrm{~Gy}(\mathrm{RBE})$, were significantly different in the coronoid process (Figure 4e, Table 1, $p=0.002$ ) but not in the mandible head (Figure 4f, Table 1, $p=0.39$ ). From the ROC curve, the cut-off value was found to be $38.0 \mathrm{~Gy}(\mathrm{RBE})$ for trismus (sensitivity, 1.0; specificity, 0.56; AUC, 0.773; Table 1). There were no cases in which trismus was absent when high doses of radiation were administered to both the temporomandibular joint-related muscles and bones.

Table 1. Cut-off value of maximum dose for the onset of trismus in temporomandibular joint-related organs.

\begin{tabular}{cccccc}
\hline Structure & $\begin{array}{c}\text { Maximum Dose Cut-Off } \\
\text { Value, Gy(RBE) }\end{array}$ & $p$-Value & Sensitivity & Specificity & AUC \\
\hline Masseter muscle & 44.0 & 0.003 & 1 & 0.44 & 0.653 \\
Temporal muscle & 39.6 & 0.013 & 1 & 0.36 & 0.607 \\
Medial pterygoid muscle & 60.4 & 0.013 & 1 & 0.29 & 0.601 \\
Lateral pterygoid muscle & 57.6 & 0.019 & 1 & 0.29 & 0.559 \\
Coronoid process & 38.0 & 0.002 & 1 & 0.56 & 0.773 \\
Mandible head & 8.2 & 0.390 & 1 & 0.16 & 0.467 \\
\hline
\end{tabular}



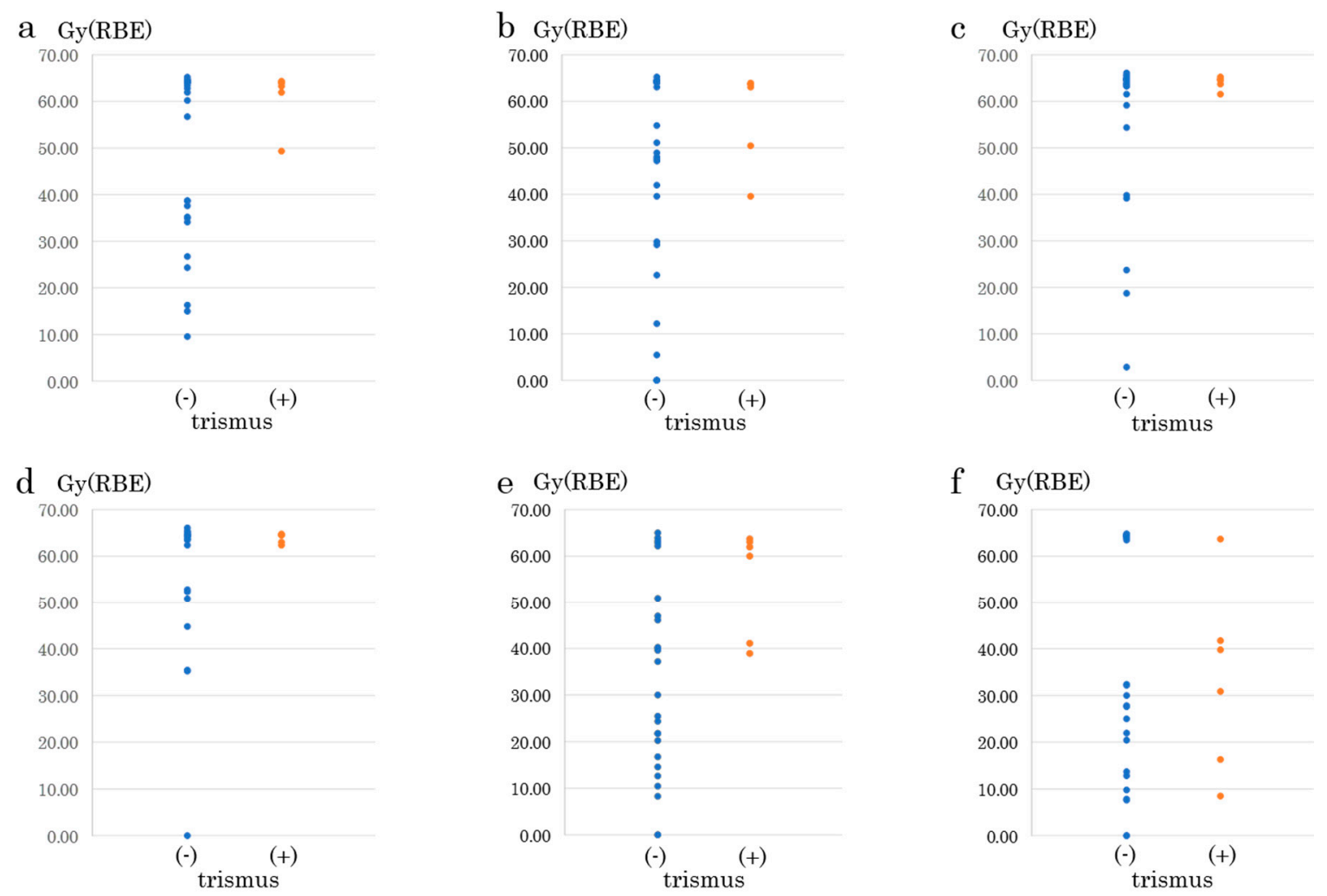

Figure 4. Relationship between maximum dose in the temporomandibular joint-related structures and carbon ion radiotherapy-induced trismus. Data are presented as mean \pm S.D. (a) Masseter muscle, (b) temporal muscle, (c) medial pterygoid muscle, (d) lateral pterygoid muscle, (e) coronoid process, (f) mandible head.

\subsection{Dose Rate of the Temporomandibular Joint-Related Structures and C-Ion RT-Induced Trismus}

The doses received by 10, 20, 30, 40, and 50\% (D10, D20, D30, D40, and D50) of the temporomandibular joint-related muscle and bone volumes, along with mean above structure dose in percentage are summarized in Table 2. The coronoid process showed significantly different doses for the presence or absence of trismus in all groups from D10 to D50 (D10; trismus 52.2 $\pm 13.0 \mathrm{~Gy}$ (RBE) without trismus, $29.3 \pm 20.5 \mathrm{~Gy}(\mathrm{RBE}) p=0.007$, D20; trismus $50.9 \pm 13.3 \mathrm{~Gy}(\mathrm{RBE})$ without trismus, $27.8 \pm 20.5 \mathrm{~Gy}(\mathrm{RBE})$ $p=0.007$, D30; trismus $49.7 \pm 13.5 \mathrm{~Gy}(\mathrm{RBE})$ without trismus, $26.7 \pm 20.4 \mathrm{~Gy}(\mathrm{RBE}) p=0.007$, D40; trismus $48.6 \pm 13.6 \mathrm{~Gy}(\mathrm{RBE})$ without trismus $25.8 \pm 20.2 \mathrm{~Gy}(\mathrm{RBE}) p=0.007$, D50; trismus $47.4 \pm 13.7 \mathrm{~Gy}(\mathrm{RBE})$ without trismus $25.0 \pm 20.0 \mathrm{~Gy}(\mathrm{RBE}) p=0.008)$. At other sites, a significant difference was observed only in D10 of the temporal muscle (with trismus $50.3 \pm 14.1 \mathrm{~Gy}(\mathrm{RBE})$ without trismus $34.2 \pm 22.2 \mathrm{~Gy}(\mathrm{RBE})$, $p=0.024)$. 
Table 2. Dose received by temporomandibular joint-related muscles and bones.

\begin{tabular}{|c|c|c|c|c|c|}
\hline \multirow{2}{*}{ Masseter Muscle } & \multicolumn{2}{|c|}{ Trismus(+) } & \multicolumn{2}{|c|}{ Trismus(-) } & \multirow{2}{*}{$p$-Value } \\
\hline & Gy (RBE) & $\pm \mathrm{SD}$ & Gy (RBE) & $\pm \mathrm{SD}$ & \\
\hline D10 & 47.7 & 10.7 & 36.9 & 20.9 & 0.118 \\
\hline D20 & 35.9 & 13.4 & 31.0 & 18.8 & 0.278 \\
\hline D30 & 30.3 & 15.0 & 26.4 & 17.5 & 0.310 \\
\hline D40 & 27.2 & 15.4 & 22.3 & 16.8 & 0.259 \\
\hline D50 & 24.9 & 15.2 & 18.7 & 16.4 & 0.204 \\
\hline \multicolumn{6}{|l|}{ Temporal muscle } \\
\hline D10 & 50.3 & 14.1 & 34.2 & 22.2 & 0.024 \\
\hline D20 & 43.4 & 13.8 & 31.4 & 21.8 & 0.105 \\
\hline D30 & 37.6 & 14.7 & 29.2 & 21.5 & 0.187 \\
\hline D40 & 32.5 & 16.0 & 27.2 & 21.1 & 0.284 \\
\hline D50 & 27.9 & 16.6 & 25.2 & 20.6 & 0.384 \\
\hline \multicolumn{6}{|c|}{ Medial pterygoid muscle } \\
\hline D10 & 58.3 & 10.0 & 44.0 & 22.7 & 0.089 \\
\hline D20 & 51.5 & 16.6 & 37.4 & 24.6 & 0.117 \\
\hline D30 & 44.8 & 21.0 & 32.3 & 25.5 & 0.163 \\
\hline D40 & 39.4 & 23.9 & 27.9 & 25.5 & 0.189 \\
\hline D50 & 35.1 & 25.8 & 24.3 & 25.2 & 0.201 \\
\hline \multicolumn{6}{|c|}{ Lateral pterygoid muscle } \\
\hline D10 & 61.2 & 5.6 & 46.7 & 22.1 & 0.075 \\
\hline D20 & 57.6 & 10.9 & 42.5 & 22.8 & 0.077 \\
\hline D30 & 53.6 & 15.5 & 39.1 & 23.0 & 0.095 \\
\hline D40 & 50.1 & 18.4 & 36.2 & 22.8 & 0.108 \\
\hline D50 & 46.9 & 20.5 & 33.4 & 22.5 & 0.116 \\
\hline \multicolumn{6}{|l|}{ Coronoid process } \\
\hline D10 & 52.2 & 13.0 & 29.3 & 20.5 & 0.007 \\
\hline D20 & 50.9 & 13.3 & 27.8 & 20.5 & 0.007 \\
\hline D30 & 49.7 & 13.5 & 26.7 & 20.4 & 0.007 \\
\hline D40 & 48.6 & 13.6 & 25.8 & 20.2 & 0.007 \\
\hline D50 & 47.4 & 13.7 & 25.0 & 20.0 & 0.008 \\
\hline \multicolumn{6}{|l|}{ Mandible head } \\
\hline D10 & 25.6 & 20.2 & 33.2 & 25.4 & 0.253 \\
\hline D20 & 24.1 & 19.9 & 32.1 & 25.5 & 0.241 \\
\hline D30 & 22.8 & 19.3 & 31.2 & 25.6 & 0.231 \\
\hline D40 & 21.7 & 18.5 & 30.3 & 25.6 & 0.222 \\
\hline D50 & 20.6 & 17.6 & 29.5 & 25.6 & 0.215 \\
\hline
\end{tabular}

\section{Discussion}

In this study, we analyzed the maximum dose and DVH associated with trismus in head and neck cancer patients treated with C-ion RT. The median follow-up time was 57 months. Grade 2 trismus was observed in six patients. The prevalence of trismus was $19.4 \%$, and the median onset time was 12 months. The prevalence of trismus induced by X-ray and C-ion RT is reported to be $1.4-41 \%$ [3-11] and 2-9\% [16-20], respectively. In this study, the prevalence of a slightly higher incidence than previously reported may be due to the tumor site; however, this difference is not significant because this is a small study. A previous study showed that the onset of trismus is associated with a median of 1-16 months after completion of X-ray radiotherapy [2,4,8-10,12,15,22,23]; however, C-ion RT-induced trismus has not been reported. Most studies on X-ray-induced trismus have defined a mouth opening distance of less than $35 \mathrm{~mm}[2,6,8-10,23]$. In contrast, as in this study, trismus in reporting C-ion RT is defined according to the CTCAE criteria [17-20,22]. 
Previous studies showed that trismus onset by $\mathrm{X}$-ray had a significant correlation with the C-ion RT dose in the masseter muscles $[1,2,6,10,12]$, pterygoid muscles $[1,13,14]$, the temporomandibular joint [2,15]. The mean dose to the masseter muscle with trismus was 57.2 Gy at D50 [6]. In another report, after a dose of $40 \mathrm{~Gy}$, for every additional $10 \mathrm{~Gy}$ radiation in the pterygoid muscle, an increase in the probability of trismus by $24 \%$ was observed [1]. However, in this study, the mean radiation doses administered to the masseter and pterygoid muscles were not significantly different for the onset of trismus at any time (D10, D20, D30, D40, and D50). Similarly, the mean radiation dose administered to muscles was not significant, except for the temporal muscle of D10; however, the radiation doses administered to muscles were significantly different for the maximum dose. In this report, a significant difference was confirmed, especially in the masseter muscle maximum dose, and the cut-off value was 44.0 Gy(RBE) for C-ion RT-induced trismus. Similar results have been reported with X-rays [1,2,6,10,12]. In contrast, in the coronoid process, there was a significant difference in both the mean dose (D10; 52.2 Gy(RBE), D20; 50.9 Gy(RBE), D30; 49.7i Gy(RBE), D40; 48.6 Gy(RBE), and D50; 47.4 Gy(RBE)) and the maximum dose (cut-off value $38.0 \mathrm{~Gy}(\mathrm{RBE})$ ) associated with the onset of trismus.

In the DVH analysis, not only the high dose of radiation received by the masseter muscle but also the low to middle dose range received by the coronoid process seemed to be associated with the development of C-ion RT-induced trismus. Therefore, the reduction of the low to moderate dose volume of the DVH of the coronoid process may be useful in preventing trismus. The maximum dose administered to the coronoid process was also significant; however, it is unlikely that the high dose to the bone structure led to the trismus; the effect of radiation on the temporal muscle (at a muscular attachment), and the tendon may also be important. In some cases, high maximum doses were found even in non-onset cases, but the maximum dose was the maximum point dose, and due to the good dose distribution characteristic of C-ion RT, high-dose sites were spotted. Considering the ratio of radiation dose to each structure, it is possible that the middle to low dose area occupies most of the structure. According to the results in the present study, at the maximum doses of radiation, all types of masticatory muscles showed a significant difference in the development of trismus, with the most significant difference observed in the masseter muscle. We can offer a dose-constraint option in the C-ion RT optimization process, including a maximum dose to the masseter muscle of approximately $44.0 \mathrm{~Gy}(\mathrm{RBE})$. Moreover, from D10 to D50, it is important to keep the radiation dose to the coronoid process to less than $47 \mathrm{~Gy}(\mathrm{RBE})$. However, the contouring of the masseter muscle and the coronoid process requires different treatment planning for radiation oncologists (Figure 2b). Since the coronoid process forms contours more easily than the masseter muscle, radiation oncologists should consider it a risk organ to prevent C-ion RT-induced trismus.

As mentioned above, for non-invading tumors, minimizing radiation exposure to temporomandibular joint-related structures by reducing the dose of radiation therapy prevents the onset of trismus. However, this dose reduction strategy is challenging when the tumor invades temporomandibular joint-related structures. Several stretching techniques and jaw mobilizing devices are currently available to treat radiotherapy-induced trismus [24,25]. Jaw opening exercises using various jaw mobilizing devices, such as the TheraBite Jaw Motion Rehabilitation System and the Dynasplint Trismus System, have been proposed for treating radiotherapy-induced trismus [24,25]. There is, however, a lack of standard jaw mobilizing devices to treat radiotherapy-induced trismus. Our institution also recommends implementing mouth opening exercises using a device for patients who experience trismus within a year after C-ion RT. Future studies should consider the appropriate timing of mouth opening exercise, duration of mouth opening exercise, and type of device used to prevent radiation-induced trismus.

This study had a few limitations. First, since this study was conducted on a small number of patients enrolled at a single institute, the primary sites of tumor initiation were not examined thoroughly. Future studies should increase the number of patients for the study design. Second, we only evaluated the CTCAE criteria. In past studies using X-rays, many studies have defined a mouth opening of less than $35 \mathrm{~mm}$ as a mouth opening disorder $[2,6,8-10,23]$. As in a previous study 
using the CTCAE criteria [3], we focused on whether it was easy to open the mouth because there are individual differences in the mouth opening disorder.

\section{Materials and Methods}

\subsection{Patients and Tumor Characteristics}

The present study is a subgroup analysis of a prospective clinical study that included 35 patients diagnosed with nonsquamous cell carcinoma of the head and neck region and treated with C-ion RT between 2010 and 2014 in our institution. This study was approved by our Institutional Review Board and registered with the University Hospital Medical Information Network in Japan (trial registration number: UMIN000007886) [16]. All patients provided informed consent before treatment. For analyzing trismus, we excluded one case with previously existing C-ion RT-induced trismus, and three patients who underwent salvage surgery for recurrence after C-ion RT. Thirty-one cases were eventually analyzed (Figure 5). Table 3 summarizes the patient and tumor characteristics. The primary cancer sites were the maxillary sinus $(n=8)$, nasal cavity $(n=8)$, parotid gland $(n=5)$, oral cavity $(\mathrm{n}=4)$, pharynx $(\mathrm{n}=4)$, and the external auditory canal $(\mathrm{n}=2)$. The 3-year local control rate $(93 \%)$ and the 3-year overall survival rate (88\%) for these patients have already been reported [16].

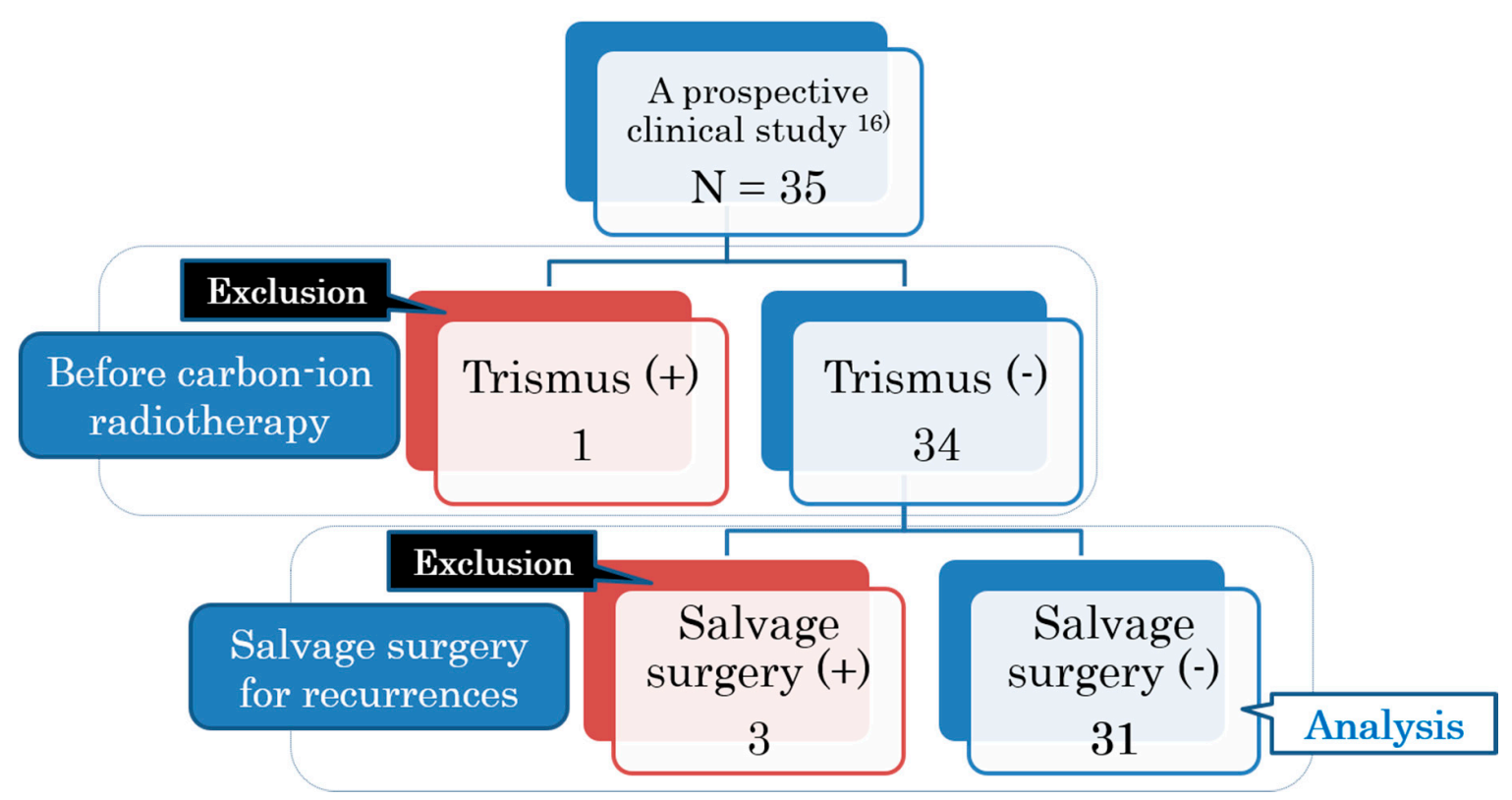

Figure 5. Patient selection criteria for the study. 
Table 3. Patient and tumor characteristics.

\begin{tabular}{|c|c|}
\hline \multicolumn{2}{|l|}{ Characteristic } \\
\hline Total $(n)$ & 31 \\
\hline Follow up time $(m)$, mean (range) & $57(6.1-87.1)$ \\
\hline Age (y) & $59(31-77)$ \\
\hline \multicolumn{2}{|l|}{ Gender, $n(\%)$} \\
\hline Male & $14(45)$ \\
\hline Female & $17(55)$ \\
\hline \multicolumn{2}{|l|}{ Primary site, $n(\%)$} \\
\hline Maxillary sinus & $8(26)$ \\
\hline Nasal cavity & $8(26)$ \\
\hline Parotid gland & $5(16)$ \\
\hline Oral cavity & $4(13)$ \\
\hline Pharynx & $4(13)$ \\
\hline External auditory canal & $2(6)$ \\
\hline \multicolumn{2}{|l|}{ Histological type, $n(\%)$} \\
\hline Adenoid cystic carcinoma & $17(55)$ \\
\hline Olfactory neuroblastoma & $5(16)$ \\
\hline Mucoepidermoid carcinoma & $4(13)$ \\
\hline Adenocarcinoma & $2(6)$ \\
\hline others & $3(10)$ \\
\hline $\begin{array}{l}\text { Gross tumor volumes }\left(\mathrm{cm}^{3}\right) \\
\text { (median: } 28.68\end{array}$ & $7.11-129.04$ \\
\hline \multicolumn{2}{|l|}{ Total dose, $n(\%)$} \\
\hline 64.0 Gy (RBE) & $29(94)$ \\
\hline 57.6 Gy (RBE) & $2(6)$ \\
\hline \multicolumn{2}{|l|}{ T stage, $n(\%)$} \\
\hline $\mathrm{T} 1$ & $0(0)$ \\
\hline $\mathrm{T} 2$ & $5(16)$ \\
\hline $\mathrm{T} 3$ & $7(23)$ \\
\hline $\mathrm{T} 4 \mathrm{a}$ & $6(19)$ \\
\hline $\mathrm{T} 4 \mathrm{~b}$ & $13(42)$ \\
\hline \multicolumn{2}{|l|}{ N stage, $n(\%)$} \\
\hline No & $31(100)$ \\
\hline \multicolumn{2}{|l|}{ M stage, $n(\%)$} \\
\hline M0 & $31(100)$ \\
\hline
\end{tabular}

\subsection{Carbon Ion Radiotherapy}

The techniques used for C-ion RT and the treatment plan have been reported previously [16]. Physical dose calculations were performed using a pencil beam algorithm. The clinical dose distribution was calculated using the physical dose and relative biological effectiveness (RBE). The dose of C-ion RT was expressed as "Gy(RBE)" (physical carbon ion dose (Gy) $\times$ RBE). The number of fractions was 16, and the overall treatment time was four weeks (4 fractions per week). Following the clinical protocol, 29 patients received $64.0 \mathrm{~Gy}(\mathrm{RBE})$ in 16 fractions, 2 patients received $57.6 \mathrm{~Gy}(\mathrm{RBE})$ (in these two patients, the mucosa and skin were considered to be widely irradiated).

\subsection{Analysis of Temporomandibular Joint Structures}

In the muscle and bone structures of the diseased side, around the temporomandibular joint, the doses of radiation received by the masseter muscle, temporal muscle, medial pterygoid muscle, 
lateral pterygoid muscle, coronoid process, and mandibular head were examined. Using commercially available software (MIM Maestro, version 6.9.3, Beachwood, OH, USA), the contour of each organ and a 3-dimensional image of the mandible (Figure $2 b$ ) were created. Trismus was evaluated using the CTCAE, version 4.0. [21] and grade 2 or higher was considered to be trismus. The relationship between the dose of radiation and trismus was analyzed in various temporomandibular joint structures.

\subsection{Statistical Analysis}

Data are represented as mean \pm standard deviation (S.D.). Statistical differences were compared using a two-sided Student's t-test. A paired t-test was used to compare differences in the maximum doses between high-grade trismus and none. ROC curves were generated to anticipate the dose at the site of trismus. All data were analyzed using SPSS Statistics software, version 26.0 (IBM Corp., Armonk, NY, USA). Differences with $p<0.05$ were considered statistically significant.

\section{Conclusions}

The masseter muscle showed the most significant difference between the presence and absence of trismus, in terms of maximum doses received among muscle tissues. The maximum and mean radiation doses that led to no trismus, or caused trismus, were significantly different in the coronoid process. The coronoid process can be suggested as a guideline for treatment planning considering the ease of contouring.

Supplementary Materials: The following are available online at http://www.mdpi.com/2072-6694/12/11/3116/s1, Table S1: Univariate analysis of risk factors for carbon ion radiotherapy-induced trismus.

Author Contributions: Conceived and designed the research: A.M.; performed the research, analyzed the data, and contributed materials/analysis tools: A.M., H.S. (Hirofumi Shimada), N.K., H.K., N.O., Y.M., H.S. (Hiro Sato) and T.O.; planned the treatment: A.M., K.S., J.-i.S. and T.O.; analyzed the treatment and contributed to the final draft of the manuscript: A.M., H.S. (Hirofumi Shimada), N.K., H.K., N.O., Y.M., H.S. (Hiro Sato) and T.O. All authors read and approved the final manuscript: A.M., H.S. (Hirofumi Shimada), N.K., H.K., N.O., Y.M., H.S. (Hiro Sato), K.S., J.S., S.Y., K.C. and T.O.

Funding: This work was supported by the Takeda Science Foundation and Project Mirai Cancer Research Grants. The study sponsors had no involvement in the study design, data collection, data analysis or interpretation, manuscript writing, or the decision to submit the manuscript for publication.

Acknowledgments: We thank Editage (www.editage.jp) for English language editing.

Conflicts of Interest: The authors declare no conflict of interest.

\section{References}

1. Teguh, D.N.; Levendag, P.C.; Voet, P.; van der Est, H.; Noever, I.; de Kruijf, W.; van Rooij, P.; Schmitz, P.I.; Heijmen, B.J. Trismus in patients with oropharyngeal cancer: Relationship with dose in structures of mastication apparatus. Head Neck 2008, 30, 622-630. [CrossRef] [PubMed]

2. Pauli, N.; Olsson, C.; Pettersson, N.; Johansson, M.; Haugen, H.; Wilderäng, U.; Steineck, G.; Finizia, C. Risk structures for radiation-induced trismus in head and neck cancer. Acta Oncol. 2016, 55, 788-792. [CrossRef] [PubMed]

3. Ou, X.; Zhou, X.; Shi, Q.; Xing, X.; Yang, Y.; Xu, T.; Shen, C.; Wang, X.; He, X.; Kong, L.; et al. Treatment outcomes and late toxicities of 869 patients with nasopharyngeal carcinoma treated with definitive intensity modulated radiation therapy: New insight into the value of total dose of cisplatin and radiation boost. Oncotarget 2015, 6, 38381-38397. [CrossRef] [PubMed]

4. Zeng, L.; Tian, Y.M.; Sun, X.M.; Chen, C.Y.; Han, F.; Xiao, W.W.; Deng, X.W.; Lu, T.X. Late toxicities after intensity-modulated radiotherapy for nasopharyngeal carcinoma: Patient and treatment-related risk factors. Br. J. Cancer 2014, 110, 49-54. [CrossRef] [PubMed]

5. Chen, Y.Y.; Zhao, C.; Wang, J.; Ma, H.L.; Lai, S.Z.; Liu, Y.; Han, F.; Lu, L.X.; Bao, Y.; Chen, M. Intensity-modulated radiation therapy reduces radiation-induced trismus in patients with nasopharyngeal carcinoma: A prospective study with $>5$ years of follow-up. Cancer 2011, 117, 2910-2916. [CrossRef] 
6. $\quad$ Lindblom, U.; Gärskog, O.; Kjellén, E.; Laurell, G.; Jäghagen, E.L.; Wahlberg, P.; Zackrisson, B.; Nilsson, P. Radiation-induced trismus in the ARTSCAN head and neck trial. Acta Oncol. 2014, 53, 620-627. [CrossRef]

7. Ichimura, K.; Tanaka, T. Trismus in patients with malignant tumours in the head and neck. J. Laryngol. Otol. 1993, 107, 1017-1020. [CrossRef]

8. Van der Geer, S.J.; Kamstra, J.I.; Roodenburg, J.L.; van Leeuwen, M.; Reintsema, H.; Langendijk, J.A.; Dijkstra, P.U. Predictors for trismus in patients receiving radiotherapy. Acta Oncol. 2016, 55, 1318-1323. [CrossRef]

9. Astradsson, T.; Laurell, G.; Ahlberg, A.; Nikolaidis, P.; Johansson, H.; Ehrsson, Y.T. Trismus in patients with head and neck cancer and 5-year overall survival. Acta Otolaryngol. 2018, 138, 1123-1127. [CrossRef]

10. Gebre-Medhin, M.; Haghanegi, M.; Robért, L.; Kjellén, E.; Nilsson, P. Dose-volume analysis of radiation-induced trismus in head and neck cancer patients. Acta Oncol. 2016, 55, 1313-1317. [CrossRef]

11. Steiner, F.; Evans, J.; Marsh, R.; Rigby, P.; James, S.; Sutherland, K.; Wickens, R.; Nedev, N.; Kelly, B.; Tan, S.T. Mouth opening and trismus in patients undergoing curative treatment for head and neck cancer. Int. J. Oral Maxillofac. Surg. 2015, 44, 292-296. [CrossRef] [PubMed]

12. Van der Molen, L.; Heemsbergen, W.D.; de Jong, R.; van Rossum, M.A.; Smeele, L.E.; Rasch, C.R.; Hilgers, F.J. Dysphagia and trismus after concomitant chemo-Intensity-Modulated Radiation Therapy (chemo-IMRT) in advanced head and neck cancer; dose-effect relationships for swallowing and mastication structures. Radiother. Oncol. 2013, 106, 364-369. [CrossRef] [PubMed]

13. Dijkstra, P.U.; Kalk, W.W.; Roodenburg, J.L. Trismus in head and neck oncology: A systematic review. Oral Oncol. 2004, 40, 879-889. [CrossRef]

14. Goldstein, M.; Maxymiw, W.G.; Cummings, B.J.; Wood, R.E. The effects of antitumor irradiation on mandibular opening and mobility: A prospective study of 58 patients. Oral Surg. Oral Med. Oral Pathol. Oral Radiol. Endod. 1999, 88, 365-373. [CrossRef]

15. Vissink, A.; Jansma, J.; Spijkervet, F.K.; Burlage, F.R.; Coppes, R.P. Oral sequelae of head and neck radiotherapy. Crit. Rev. Oral Biol. Med. 2003, 14, 199-212. [CrossRef] [PubMed]

16. Shirai, K.; Saitoh, J.I.; Musha, A.; Abe, T.; Kobayashi, D.; Takahashi, T.; Tamaki, T.; Kawamura, H.; Takayasu, Y.; Shino, M.; et al. Prospective observational study of carbon-ion radiotherapy for non-squamous cell carcinoma of the head and neck. Cancer Sci. 2017, 108, 2039-2044. [CrossRef] [PubMed]

17. Jensen, A.D.; Uhl, M.; Chaudhri, N.; Herfarth, K.K.; Debus, J.; Roeder, F. Carbon Ion irradiation in the treatment of grossly incomplete or unresectable malignant peripheral nerve sheaths tumors: Acute toxicity and preliminary outcome. Radiat. Oncol. 2015, 10, 109. [CrossRef]

18. Koto, M.; Demizu, Y.; Saitoh, J.I.; Suefuji, H.; Tsuji, H.; Okimoto, T.; Ohno, T.; Shioyama, Y.; Ikawa, H.; Nemoto, K.; et al. Definitive carbon-ion radiation therapy for locally advanced sinonasal malignant tumors: Subgroup analysis of a multicenter study by the Japan Carbon-Ion Radiation Oncology Study Group (J-CROS). Int. J. Radiat. Oncol. Biol. Phys. 2018, 102, 353-361. [CrossRef]

19. Abe, T.; Ohno, T.; Koto, M.; Demizu, Y.; Suefuji, H.; Tsuji, H.; Okimoto, T.; Shioyama, Y.; Saitoh, J.I.; Shirai, K.; et al. A multi-institutional retrospective study of carbon-ion radiotherapy for non-squamous cell malignant tumors of the nasopharynx: Subanalysis of Japan Carbon-Ion Radiation Oncology Study Group study 1402 HN. Cancer Med. 2018, 7, 6077-6083. [CrossRef]

20. Sulaiman, N.S.; Demizu, Y.; Koto, M.; Saitoh, J.I.; Suefuji, H.; Tsuji, H.; Ohno, T.; Shioyama, Y.; Okimoto, T.; Daimon, T.; et al. Multicenter study of carbon-ion radiation therapy for adenoid cystic carcinoma of the head and neck: Subanalysis of the Japan Carbon-Ion Radiation Oncology Study Group (J-CROS) Study (1402 HN). Int. J. Radiat. Oncol. Biol. Phys. 2018, 100, 639-646. [CrossRef]

21. National Cancer Institute Common Terminology Criteria for Adverse Events (CTCAE) v.4.0. Available online: http://evs.nci.nih.gov/ftp1/CTCAE/About.html (accessed on 1 September 2020).

22. Wang, C.J.; Huang, E.Y.; Hsu, H.C.; Chen, H.C.; Fang, F.M.; Hsiung, C.Y. The degree and time-course assessment of radiation-induced trismus occurring after radiotherapy for nasopharyngeal cancer. Laryngoscope 2005, 115, 1458-1460. [CrossRef] [PubMed]

23. Pauli, N.; Mejersjö, C.; Fagerberg-Mohlin, B.; Finizia, C. Temporomandibular disorder in head and neck cancer patients undergoing radiotherapy: Clinical findings and patient-reported symptoms. Head Neck 2019, 41, 3570-3576. [CrossRef] [PubMed] 
24. Van der Geer, S.J.; Reintsema, H.; Kamstra, J.I.; Roodenburg, J.L.N.; Dijkstra, P.U. The use of stretching devices for treatment of trismus in head and neck cancer patients: A randomized controlled trial. Support Care Cancer. 2020, 28, 9-11. [CrossRef]

25. Scherpenhuizen, A.; van Waes, A.M.; Janssen, L.M.; Van Cann, E.M.; Stegeman, I. The effect of exercise therapy in head and neck cancer patients in the treatment of radiotherapy-induced trismus: A systematic review. Oral Oncol. 2015, 51, 745-750. [CrossRef]

Publisher's Note: MDPI stays neutral with regard to jurisdictional claims in published maps and institutional affiliations.

(C) 2020 by the authors. Licensee MDPI, Basel, Switzerland. This article is an open access article distributed under the terms and conditions of the Creative Commons Attribution (CC BY) license (http://creativecommons.org/licenses/by/4.0/). 